Cite this: Nanoscale, 2014, 6, 263

\title{
Electrophoretic deposition as a new approach to produce optical sensing films adaptable to microdevices $\dagger$
}

\author{
Marta Marín-Suárez, ${ }^{\text {*a }}$ Santiago Medina-Rodríguez, ${ }^{\text {ab }}$ Olgaç Ergeneman, ${ }^{\text {*c }}$ \\ Salvador Pané, ${ }^{c}$ Jorge F. Fernández-Sánchez, ${ }^{a}$ Bradley J. Nelson ${ }^{c}$ \\ and Alberto Fernández-Gutiérrez ${ }^{a}$
}

We report the fabrication of optical oxygen sensor films using electrophoretic deposition (EPD) of poly(styrene-co-maleic anhydride) nanoparticles containing the oxygen-sensitive dye platinum(॥) mesotetra(pentafluorophenyl)porphine. Compared to other deposition methods, the EPD is simple and allows easy control over deposition, which is crucial for the implementation of optical sensing films in microdevices. By optimizing the synthesis of the functional nanoparticles, anodic EPD can be performed. The amount of deposited particles can be tuned by varying either the electrical potential or the deposition time. The sensing phases were characterized using a phase-modulation technique showing a Stern-Volmer constant $\left(k_{\mathrm{SV} 1}\right)$ between 45 and $52 \mathrm{bar}^{-1}$ for gas and of $20.72 \mathrm{bar}^{-1}$ in the aqueous phase without leaching of the particles from the surface. The small thickness of the layers lead to short response times $(<0.4 \mathrm{~s})$. This is the first time that polymeric optical sensing films have been obtained by EPD from dispersions of oxygen sensing nanoparticles.

Received 28th June 2013 Accepted 2nd October 2013

DOI: $10.1039 / \mathrm{c} 3 \mathrm{nr} 03336 \mathrm{~h}$

www.rsc.org/nanoscale applications, ${ }^{7,12}$ including minimally invasive detection of oxygen inside the eye. ${ }^{\mathbf{1 1}, \mathbf{1 3}, \mathbf{1 4}}$ In order to confer sensing functionalities to the microrobot, methods to integrate sensing blocks are urgently required. The functionalization of threedimensional structures such as the one presented by Ergeneman et al. ${ }^{\mathbf{1 1}}$ is challenging. The integration of the sensing material should be uniform in thickness and conformal. The available optical sensing films such as membranes, nanoparticles, paints, and fibers cannot be easily incorporated into microstructures without compromising the uniformity of the layer thickness.

This paper proposes a method based on electrophoretic deposition (EPD) to integrate oxygen-sensitive nanoparticles in arbitrary shapes. This technique enables the integration of films in a conformal manner. ${ }^{15,16}$ In EPD, charged nanoparticles dispersed in a liquid move towards a conductive substrate of opposite charge on which they are deposited. ${ }^{17}$ Consequently, deposition can be performed over a wide range of microarchitectures. Moreover, the film thickness can be controlled by simply adjusting the deposition time and the applied potential.

EPD is of considerable interest for a wide range of applications due to its simplicity and low cost, and it has been successfully applied to deposit a variety of materials, ${ }^{15,17,18}$ including different types of nanoparticles and composites for optical sensors. ${ }^{19-21}$ In this area, Yarimaga et al. used EPD to create micropatterns of polydiacetylene, which show heatinduced non-fluorescence to fluorescence switching. The authors investigate the in situ polymerization and its suitability 
to monitor temperature in microheaters. ${ }^{19}$ Sun et al. have also used EPD to produce films with selective detection of mercury by fluorescence quenching. This film is based on a mercury sensitive fluorophore 1-amino-8-naphthol-3,6-disulfonic acid sodium and layered double hydroxides (LDHs). ${ }^{20}$ The same authors developed an optical $\mathrm{pH}$ sensor based on LDHs and fluorescein. ${ }^{21}$

On the other hand, we perform EPD from dispersions of polymeric nanoparticles (defined here as solid colloidal particles with a diameter below $300 \mathrm{~nm}$ ) that act as carriers of oxygen-sensitive dyes, namely, platinum(II) meso-tetra(pentafluorophenyl)porphine (PtTFPP). The excited triplet states of this metalloporphyrin are quenched effectively with dynamic quenchers, such as oxygen, nitrogen oxides, etc. ${ }^{22,23}$ The permeability of the polymer nanoparticles to molecular oxygen enables a selective interaction of $\mathrm{O}_{2}$ with the luminescent PtTFPP and the quenching can be used to determine the oxygen concentration. The amount of polymer used in the synthesis of the particles was optimized in order to obtain appropriate particle size with a narrow size distribution for EPD. Potentials and deposition times were also investigated. In addition, the optical characterization of the resulting sensing films has been fully investigated using a phase-resolved method. The films showed both good sensitivity to oxygen and shorter response times than currently reported polymeric membranes.

\section{Experimental}

\subsection{Reagents}

Poly(styrene-co-maleic anhydride) polymer (PSMA, 7\% maleic anhydride, $M_{\mathrm{w}}=224000 \mathrm{~g} \mathrm{~mol}^{-1}$ ), tetrahydrofuran (THF), acetone, isopropanol, sodium hydroxide $(\mathrm{NaOH})$, and hydrochloric acid ( $\mathrm{HCl}, 37 \%)$ were purchased from Sigma Aldrich. Oxygen indicator Pt(II) meso-tetra(pentafluorophenyl)porphine (PtTFPP) was purchased from Frontier Scientific (http:// www.frontiersci.com/). Piranha solution consisted of a $3: 1$ mixture of concentrated sulfuric acid and 30\% hydrogen peroxide (both from Sigma Aldrich).

\subsection{Preparation and characterization of the nanoparticles}

The nanoparticles were prepared following the procedure described elsewhere. ${ }^{24}$ Briefly, $100 \mathrm{mg}$ of PSMA $(0.1 \% \mathrm{w} / \mathrm{v})$ and $1.5 \mathrm{mg}$ of PtTFPP $(1.5 \% \mathrm{w} / \mathrm{W}$ respect to the polymer) were dissolved in $100 \mathrm{~mL}$ of THF. $6 \mathrm{~mL}$ of the cocktail were subsequently dropped over $10 \mathrm{~mL}$ of deionized water under agitation. The mixture was exposed to blown air for at least 20 minutes until THF was evaporated. The resulting polymeric particles with the embedded dye formed stable dispersions. $\mathrm{NaOH}$ or $\mathrm{HCl}$ was used to adjust the $\mathrm{pH}$ of the dispersion of particles.

Particle mean diameter $(d$, in $\mathrm{nm})$, size distribution (PdI), zeta potential $(\zeta$, in $\mathrm{mV})$, and conductivity $\left(C\right.$, in $\left.\mathrm{mS} \mathrm{cm}^{-1}\right)$ of the particle dispersion were measured with a Zetananosizer (Malvern Instrument, model Zetasizer Nano ZS, http:// www.malvern.com), which is equipped with a laser and a dynamic light scattering (DLS) detector.

\subsection{Electrophoretic deposition}

A homemade electrophoretic cell was built by placing an acrylglass compartment (polymethylmethacrylate) on a platinized titanium plate sheet (purchased from http:/www.tishop.com) that acted as the cathode. The anode consisted of a $1 \mathrm{~cm}^{2}$ silicon chip coated with a $25 \mathrm{~nm}$ titanium adhesion layer and a $50 \mathrm{~nm}$ gold seed layer both obtained by means of e-beam evaporation. The chips were cleaned using acetone, isopropanol, and piranha, respectively, in order to remove organic contamination. The chips were placed facing the platinized plate keeping a constant distance of $5 \mathrm{~mm}$. A schematic drawing is presented in Fig. 1 .

The platinum cathode and the gold chip anode were connected to a programmable DC power supply (Promax, model FA665, http://www.promaxelectronics.com) in order to perform EPD. After the deposition, the chips were rinsed with deionized water and dried with nitrogen to remove all non-attached particles.

\subsection{Measurements}

Excitation and emission spectra were obtained with a Varian Cary-Eclipse luminescence spectrometer (Varian Inc.-Agilent Technologies, http://www.agilent.com, CA, USA) equipped with a Xe flash lamp (peak power equivalent to $75 \mathrm{~kW}$ ), CzernyTurner monochromators, and a red-sensitive photomultiplier tube (PMT) R-928 from Hamamatsu Photonics (http:// www.sales.hamamatsu.com, Japan) with a manual or automatic voltage regulator. In addition, a customized version of the optical fiber measurement system previously described ${ }^{25}$ (see Fig. ESI-1†) was used to characterize the sensitivity to oxygen of the sensing layers. For this purpose, the phaseresolved method described in the ESI $\dagger$ was applied using a commercial dual lock-in amplifier as the phase-sensitive detector. The phase shift $(\Phi)$ measurements at different oxygen concentrations were used to calculate the lifetime and characterize the oxygen sensitivity of the materials, while the

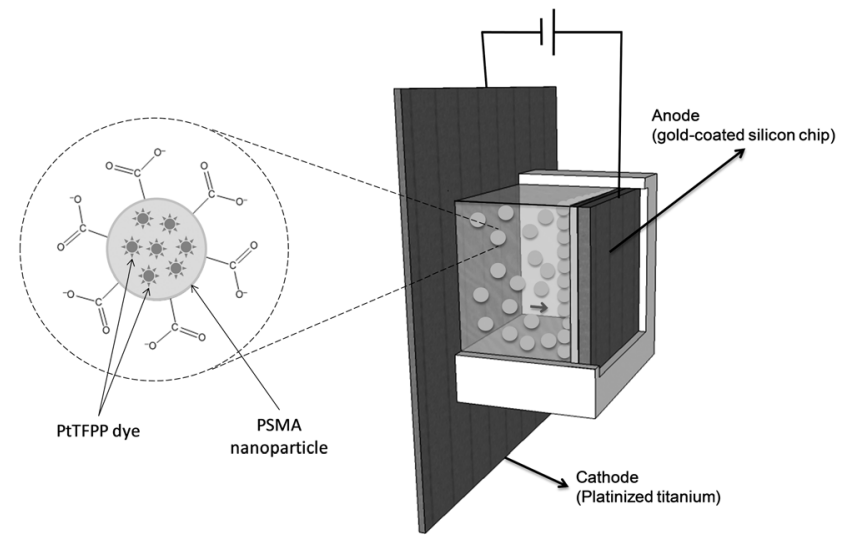

Fig. 1 Schematic drawing of the electrophoretic cell containing a dispersion of oxygen-sensitive polymeric nanoparticles. The magnified picture shows a single nanoparticle with PtTFPP molecules entrapped in the PSMA particle. The carboxylate groups confer the nanoparticle a negative charge. 
magnitude or amplitude $(R)$ measurements (proportional to the emission intensity) of the modulated emission signal were employed to extract information about the amount of particles deposited and their adhesion to the gold surface. The selection of the modulation frequency for these measurements is also described in Fig. ESI- $2 . \dagger$

For the gas characterization, the sensing phase was placed inside a homemade flow-through cell and different mixtures of nitrogen and oxygen gases (supplied by $50 \mathrm{~L}$ gas bottles at 200 bars with nitrogen 60 and oxygen 55, Air Liquide) were passed through the cell. The flow cell was made of black polytetrafluoroethylene to prevent stray reflections and to assure the chemical inertness. Both the flow cell and the PMT were housed in a dark room (Thorlabs GmbH, model XE25C1) to prevent interference from stray light and temperature was monitored during all the experiments. For gas mixing, two mass-flow controllers (MFCs) (Bronkhorst High-Tech, model EL-FLOW Select F-201CV, http://www.bronkhorst.com) were used. After the MFCs, copper and stainless steel tubing was used to connect the MFCs with the flow-through cell. The system was fully controlled from a PC using a self-made program written in Matlab 7.10 (http://www.mathworks.com) and LabView 8.5 (http://www.ni.com).

For the determination of dissolved oxygen, the same cell was filled with water at a constant flow rate of $1 \mathrm{~mL} \mathrm{~min}^{-1}$ using a peristaltic pump (Gilson Inc., model Minipuls 3, http:// www.gilson.com). The dissolved oxygen present in the water was adjusted by blowing different ratios of oxygen and nitrogen with the aforementioned gas setup. A commercial Clark electrode (Eutech Instruments, model CyberScan PCD-650, http:// www.eutechinst.com) was used to monitor the oxygen concentration in the aqueous phase.

\section{Results and discussion}

\subsection{Synthesis optimization of the $\mathrm{O}_{2}$ sensing nanoparticles}

The oxygen sensing nanoparticles contain the dye PtTFPP, whose luminescence is quenched in the presence of oxygen, immobilized in the PSMA polymer. PtTFPP is one of the most widely used dyes for the preparation of optical oxygen sensing films due to its good photostability, ${ }^{26}$ long lifetime of emission, wide excitation range, and large Stokes shift, which simplifies the measurement system. ${ }^{25,27}$ On the other side, polymeric materials have demonstrated good properties in terms of solubility of the dye and permeability to oxygen. ${ }^{8}$ Here, the role of the maleic anhydride in PSMA is also significant: when it reacts with water, the produced carboxyl groups provide negative charges to the particles' surface. ${ }^{24,28}$ This charge is responsible not only for the stability of the particle dispersion but also for the attraction of the particles to the anode to perform EPD. In addition, the presence of carboxyl groups may be interesting for further modification of the films, functionalization or covalent binding, e.g. with enzymes or antibodies for the development of biosensing phases. ${ }^{24,28,29}$

Polymeric nanoparticles with an embedded oxygen indicator can be produced by several methods, such as covalent attachment to the polymer, swelling, or physical entrapment of the dye. ${ }^{24,28,30,31}$ Precipitation-evaporation (or solvent displacement method $)^{24}$ is an easy way to produce nanoparticles with a good control over their physical properties, and thus, it was selected to produce the oxygen-sensitive particles. This method requires a water-miscible solvent able to dissolve both the dye and the polymer, such as THF. In this way, when the solvent reaches water, nanoparticles are formed due to the hydrophobicity of the polymer and the lipophilic oxygen indicator gets entrapped inside them. In all the experiments the concentration of the dye was kept at $1.5 \% \mathrm{w} / \mathrm{w}$ with respect to the polymer in order not to exceed the solubility of the dye in the polymer, which produces aggregation and self-quenching. ${ }^{32}$ In addition, the concentration of the polymer $\left(C_{\mathrm{p}}\right)$ was also kept at $0.1 \% \mathrm{w} / \mathrm{v}$ in order to ensure a good size distribution of the particles because aggregates appeared for higher PSMA concentrations.

The amount of polymer used in precipitation-evaporation can influence the size and the polydispersity of the obtained particles. ${ }^{24}$ To evaluate this effect, the volume of the polymer solution $(o)$ was varied, keeping $C_{\mathrm{p}}$ and volume of water $(w)$ constant. Fig. 2a shows the size $(d)$ and size distribution (PdI) obtained for different $o / w$ ratios. When the $o / w$ ratio increased the particles became greater in size. However, the polydispersity of the particles is hardly influenced by the $o / w$ ratio due to the low initial polymer concentration in the discontinuous phase $(0.1 \% \mathrm{w} / \mathrm{v})$ and in all cases the PdI is below 0.1, indicating a good homogeneity for all of them. ${ }^{30} \mathrm{~A}$ good homogeneity usually improves the performance of EPD because the particles move approximately at the same speed and a higher ordered packed area is expected than for those particles with a wider size distribution. ${ }^{17}$ Therefore, as all the obtained particles show good homogeneity, only size was considered to select the $o / w$ ratio. It was set at 0.6 in order to obtain particles with an appropriate amount of oxygen-sensing dye. It provides particles of $280 \mathrm{~nm}$ and PdI of 0.06 .

\subsection{Optimization of the electrophoretic deposition}

To perform EPD, the zeta potential and conductivity of the particle dispersion are important factors. ${ }^{17,33}$ The zeta potential, which is proportional to the electrophoretic mobility, indicates

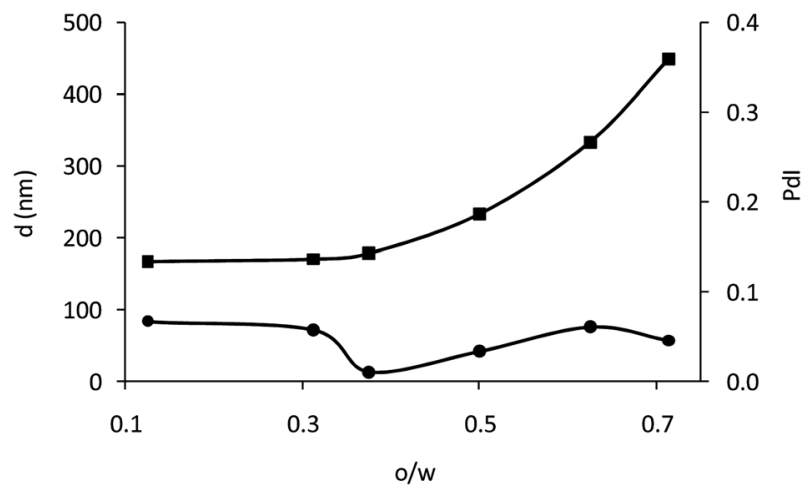

Fig. 2 (ם) Size $(d, n m)$, and (O) size distribution (Pdl) of the PSMA nanoparticles obtained by the precipitation-evaporation method with different $\mathrm{o} / \mathrm{w}$ ratios and an initial polymer loading of $0.1 \% \mathrm{w} / \mathrm{v}$. 
Table 1 Influence of $\mathrm{pH}$ over the zeta potential and conductivity of the dispersion of nanoparticles produced with an $o / w=0.6$

\begin{tabular}{lcc}
\hline $\mathrm{pH}$ & $\zeta(\mathrm{mV})$ & $C\left(\mathrm{mS} \mathrm{cm}^{-1}\right)$ \\
\hline 2.0 & -1.87 & 10.7 \\
6.5 & -33.0 & 0.125 \\
11 & -39.1 & 16.0 \\
$6.5(\text { diluted } 1: 4)^{a}$ & -33.5 & 0.028
\end{tabular}

${ }^{a}$ Dilution obtained with $1 \mathrm{~mL}$ of the dispersion of particles and $3 \mathrm{~mL}$ of deionized water.

the degree of repulsion between adjacent particles. Therefore, a high zeta potential ( $\zeta$ in $\mathrm{mV}$ ), in absolute value, is desirable as it improves the mobility while avoiding the sedimentation of the particles during EPD. ${ }^{17}$ In all the cases the absolute value of $\zeta$ is higher than $30 \mathrm{mV}$, which is considered inside the range for dispersion stability. ${ }^{34}$

In addition, $\mathrm{pH}$ has a strong influence over zeta potential and its adjustment improves the stability of nanoparticles and electrophoretic mobility. ${ }^{17,33}$ Table 1 shows $\zeta$ and conductivity $\left(C\right.$ in $\left.\mathrm{mS} \mathrm{cm}^{-1}\right)$ of the dispersion of nanoparticles $(o / w=0.6)$ when changing the $\mathrm{pH}$. $\zeta$ of the dispersion is improved from -33 to $-39 \mathrm{mV}$ when a base is added. Since the particles are negatively charged, the addition of acid neutralizes the negative charge, while adding base increases $\zeta$, thus increasing the stability. The negative effect of ionic strength on $\zeta$ can be neglected compared to the increase due to $\mathrm{pH}$.

These results can be better understood bearing in mind that the PSMA copolymer has two different classes of carboxyl groups. ${ }^{35,36}$ Primary carboxyl groups have a $\mathrm{p} K_{\mathrm{a} 1}$ around 4-5 while secondary ones possess a $\mathrm{p} K_{\mathrm{a} 2}$ of around $9-10 .{ }^{36-38}$ At $\mathrm{pH} 2$ both types of carboxylic groups are protonated and the charge is almost neutral, leading to a $\zeta$ close to 0 . At pH 11 almost all carboxylic groups are deprotonated, resulting in strongly negative charge with a $\zeta$ close to $-40 \mathrm{mV}$.

It should be highlighted that the delimitation of deposition time $(t)$ and potential $(E)$ is crucial because when EPD is performed over an aqueous solution, electrolysis of water is a common concern, even at low potential. ${ }^{\mathbf{1 7}}$ Water electrolysis may cause $\mathrm{pH}$ changes in the electrodes as well as gas evolution which may disturb the deposition process. In addition, aqueous EPD produces high current densities that lead to Joule heating and etching of the electrodes. ${ }^{17}$ For nanoparticles stabilized a) $10 \mathrm{~V} \mathrm{~cm}^{-1}-1 \mathrm{~min}$

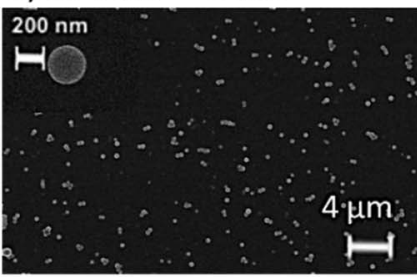

d) $20 \mathrm{~V} \mathrm{~cm}^{-1}-1 \mathrm{~min}$

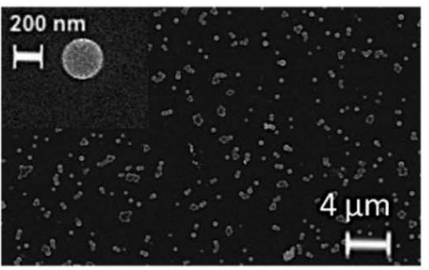

g) $30 \mathrm{~V} \mathrm{~cm}^{-1}-1 \mathrm{~min}$

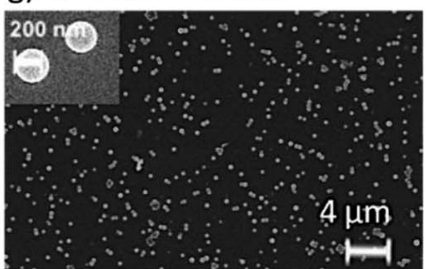

j) $40 \mathrm{~V} \mathrm{~cm}^{-1}-1 \mathrm{~min}$

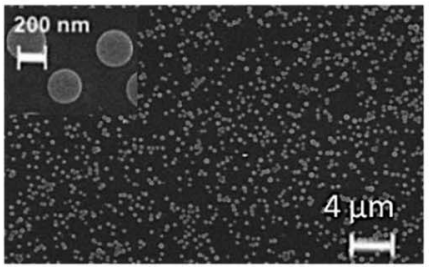

b) $10 \mathrm{~V} \mathrm{~cm}^{-1}-5 \mathrm{~min}$

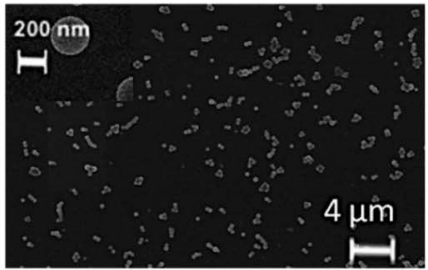

e) $20 \mathrm{~V} \mathrm{~cm}^{-1}-5 \mathrm{~min}$

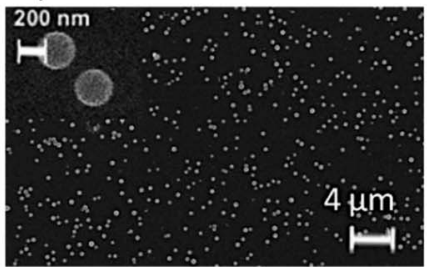

h) $30 \mathrm{~V} \mathrm{~cm}^{-1}-5 \mathrm{~min}$

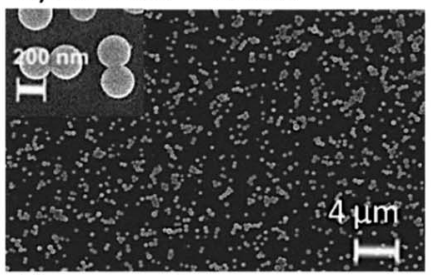

k) $40 \mathrm{~V} \mathrm{~cm}^{-1}-5 \mathrm{~min}$

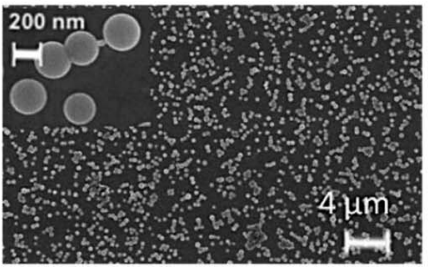

c) $10 \mathrm{~V} \mathrm{~cm}^{-1}-10 \mathrm{~min}$

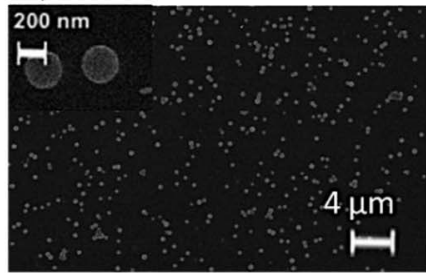

f) $20 \mathrm{~V} \mathrm{~cm}^{-1}-10 \mathrm{~min}$

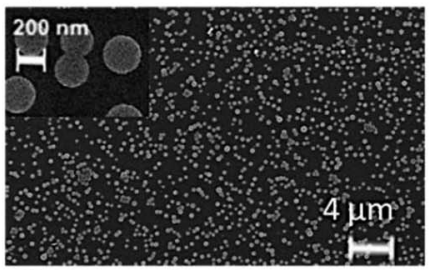

i) $30 \mathrm{~V} \mathrm{~cm}^{-1}-10 \mathrm{~min}$

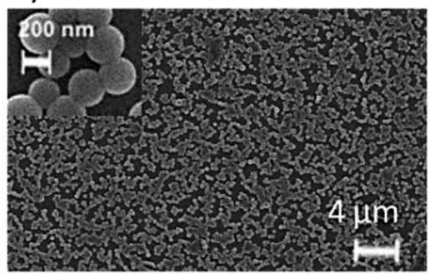

I) $40 \mathrm{~V} \mathrm{~cm}^{-1}-10 \mathrm{~min}$

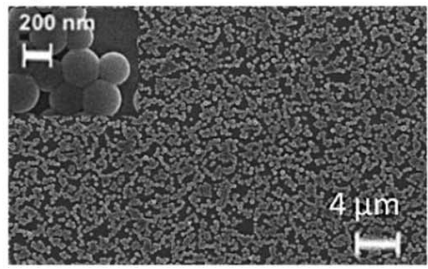

Fig. 3 Scanning electron microscopy images for the chips undergoing (a) $10 \mathrm{~V} \mathrm{~cm}^{-1} / 1 \mathrm{~min}$; (b) $10 \mathrm{~V} \mathrm{~cm}^{-1} / 5 \mathrm{~min}$; (c) $10 \mathrm{~V} \mathrm{~cm}-1 / 10 \mathrm{~min}$; (d) $20 \mathrm{~V}$ $\mathrm{cm}^{-1} / 1 \mathrm{~min}$; (e) $20 \mathrm{~V} \mathrm{~cm}^{-1} / 5 \mathrm{~min}$; (f) $20 \mathrm{~V} \mathrm{~cm}^{-1} / 10 \mathrm{~min}$; (g) $30 \mathrm{~V} \mathrm{~cm}^{-1} / 1 \mathrm{~min}$; (h) $30 \mathrm{~V} \mathrm{~cm}^{-1} / 5 \mathrm{~min}$; (i) $30 \mathrm{~V} \mathrm{~cm}-1 / 10 \mathrm{~min}$; (j) $40 \mathrm{~V} \mathrm{~cm}-1 / 1 \mathrm{~min}^{-}$(k) 40 $\mathrm{V} \mathrm{cm}-1 / 5 \mathrm{~min}$; and (l) $40 \mathrm{~V} \mathrm{~cm}^{-1} / 10 \mathrm{~min}$. 
with a base $(\zeta=-39.1 \mathrm{mV})$, the increase of conductivity $(C=$ $16.0 \mathrm{mS} \mathrm{cm}{ }^{-1}$ compared to $0.125 \mathrm{mS} \mathrm{cm}^{-1}$ for the base-free dispersion) leads to the darkening of the polymer when deposition takes place, even at low potentials and deposition times.

For the base-free dispersion $(\zeta=-33.0 \mathrm{mV}, C=$ $0.125 \mathrm{mS} \mathrm{cm}^{-1}$ ), a high level of bubble formation within a nonhomogeneous deposition was observed, which suggests that a high current transport still exists. To minimize these effects, the base-free dispersion was diluted several times and different potentials and deposition times were screened until suitable working conditions were found for a successful EPD. For a dilution $1: 4$ (with $1 \mathrm{~mL}$ of the dispersion of particles and $3 \mathrm{~mL}$ of deionized water) successful EPD was reached for an applied potential between 10 and $40 \mathrm{~V} \mathrm{~cm}^{-1}$ and deposition times between 1 and 10 minutes. Higher potentials or deposition times led to the darkening of the deposit, probably because of Joule heating of the polymer and the electrochemical etching of the deposit. ${ }^{17}$ In addition, below $10 \mathrm{~V} \mathrm{~cm}^{-1}$ or deposition times shorter than $1 \mathrm{~min}$, no homogeneous deposition over the whole surface was obtained. Therefore, the influence over the morphology and oxygen sensing properties of the films was studied within these ranges, applying potentials of 10, 20, 30 and $40 \mathrm{~V} \mathrm{~cm}^{-1}$ and deposition times of 1, 5 and $10 \mathrm{~min}$.

The morphology of the deposits obtained for each of these conditions was investigated using scanning electron microscopy (SEM). Fig. 3 shows the SEM images of the chips undergoing 10, 20,30, and $40 \mathrm{~V} \mathrm{~cm}^{-1}$ for the different deposition times. It can be noticed that for the same deposition time, the amount of particles increases with potential. For the chips undergoing $10 \mathrm{~V} \mathrm{~cm}^{-1}$, the amount of particles is hardly influenced when time is increased compared to the rest of the potentials (see Fig. 3(a)-(c)). However, for the rest of the sensing films $\left(20 \mathrm{~V} \mathrm{~cm}^{-1}, 30 \mathrm{~V} \mathrm{~cm}^{-1}\right.$ and $\left.40 \mathrm{~V} \mathrm{~cm}^{-1}\right)$ the amount of particles increases for higher deposition times (Fig. 3(d)-(f)). Fig. 3 also confirms that the nanoparticles produced by the precipitation-evaporation method are spherical and their $d$ and PdI are in agreement with the DLS measurements. In addition, it can be observed that the EPD produces a homogeneous distribution of the particles over the surfaces, with a monolayer

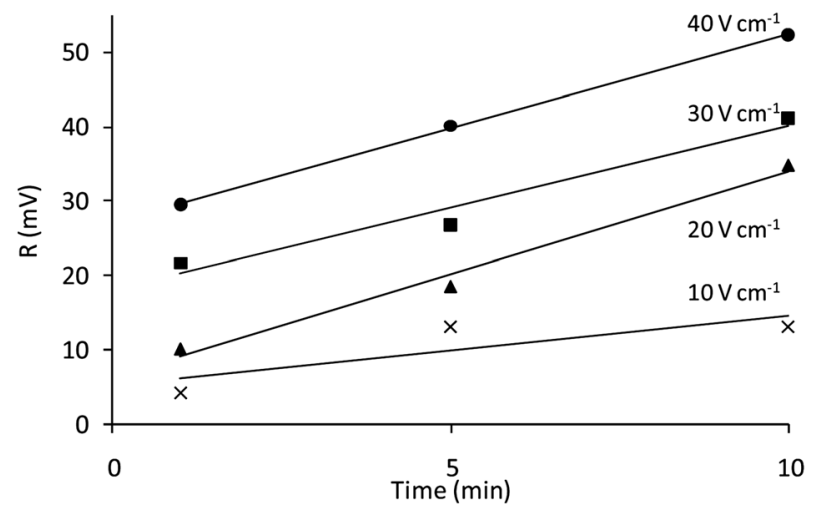

Fig. 4 Magnitude $(R, \mathrm{mV})$ of the emission collected at the different deposition times for an applied potential of $10 \mathrm{~V} \mathrm{~cm}^{-1}(X), 20 \mathrm{~V} \mathrm{~cm}^{-1}$ $(\boldsymbol{\Delta}), 30 \mathrm{~V} \mathrm{~cm}^{-1}(\boldsymbol{\square})$ and $40 \mathrm{~V} \mathrm{~cm}^{-1}(\mathbf{)})$ in the absence of oxygen. of particles. The thickness can be therefore considered as the diameter of the nanoparticles, i.e. $\approx 250 \mathrm{~nm}$.

The luminescence emission of the films in the absence of oxygen (given by the magnitude of the modulated emission signal, $R$ ) can be related to the amount of luminescent particles deposited. Following the equation proposed by Hamaker ${ }^{39}$ for electrophoretic cells with planar geometry, a theoretical deposited mass per unit area $\left(m, \mathrm{mg} \mathrm{cm}{ }^{-2}\right)$ was calculated (see Fig. 4, ESI $\dagger$ ). ESI $\dagger$ also shows the relationship between $R$ and its theoretical value of deposited mass for each condition of potential and time, confirming their relationship. Thus, $R$ was used as a guide to study the influence of deposition potential and time on the amount of particles deposited by EPD, which is increased when increasing either the time or the applied potential (Fig. 4). The deposition rate is similar for all potentials. These results are in good agreement with the micrographs shown in Fig. 3. As expected, the higher value of $R$ was found at $40 \mathrm{~V} \mathrm{~cm}^{-1}$ and $10 \mathrm{~min}$.

\subsection{Spectroscopic properties and oxygen sensitivity}

The luminescence spectra were recorded in order to evaluate the possible changes in the spectroscopic behavior of the oxygen-sensitive films once the nanoparticles had undergone an applied potential. ESI- $3 \dagger$ shows the excitation and emission spectra of the chip obtained at the highest potential and time (40 $\mathrm{V} \mathrm{cm}^{-1}$ and $10 \mathrm{~min}$ ), showing no change in the spectroscopic properties compared to the dye in solution or in a classical polystyrene (PS) membrane. ${ }^{25,40}$ It shows three excitation peaks, at $\sim 390,508$ and $540 \mathrm{~nm}$, corresponding to the Soret and $Q$ bands of platinum porphyrins. In addition, the emission peak at $650 \mathrm{~nm}$ was completely quenched in the presence of oxygen.

In order to evaluate the oxygen sensitive properties of the films, the phase shift was recorded using the phase-modulation method (see ESI $\dagger$ ) and the setup is described in Fig. ESI- $1 . \dagger$ Assuming that the luminescence decay is monoexponential, the relationship between the emission lifetime $\tau$ (in seconds) and the phase shift $\Phi$ (in radians) is given by expression (1), where $f$ is the modulation frequency (in $\mathrm{Hz}$ ). ${ }^{9,25}$

$$
\tau=\frac{\tan \Phi}{2 \pi f}
$$

Fig. ESI- $2 \uparrow$ describes the procedure for the selection of the optimal $f$ necessary for the phase-shift measurements. The modulation frequency was set at $5145 \mathrm{~Hz}$ as a compromise between the maximum phase-shift for each range of $\mathrm{O}_{2}$ concentrations and the signal-to-noise ratio (SNR) for the signal reaching the photodetector, which decreases with frequency.

Table 2 shows the lifetime of all the sensing films in the absence and in the presence of $20 \%$ of oxygen, confirming that the lifetime is not influenced by the amount of particles. In addition, no change in the lifetime was observed when comparing the lifetime of the chips with a classical liquid membrane based on the same polymer deposited in a glass support (in both cases $\tau_{0}$ is around $65 \mu \mathrm{s}$ ). Although gold is known to quench the luminescence of some molecules, ${ }^{41}$ this 
Table 2 Lifetime and Demas parameters obtained for each potential and time of deposition

\begin{tabular}{|c|c|c|c|c|c|c|c|c|}
\hline$E\left(\mathrm{~V} \mathrm{~cm}^{-1}\right)$ & $t(\min )$ & $\tau_{0}^{a, b}(\mu \mathrm{s})$ & $\tau_{20}^{a, c}(\mu \mathrm{s})$ & \multicolumn{5}{|c|}{ Demas model $^{a}$} \\
\hline & 5 & $63.53 \pm 2.35$ & $13.48 \pm 0.54$ & $0.82 \pm 0.00$ & $46.37 \pm 0.55$ & $0.19 \pm 0.00$ & $2.12 \pm 0.13$ & 0.9999 \\
\hline & 10 & $61.83 \pm 2.03$ & $13.44 \pm 0.58$ & $0.82 \pm 0.00$ & $46.28 \pm 1.17$ & $0.19 \pm 0.01$ & $1.96 \pm 0.36$ & 0.9999 \\
\hline 20 & 1 & $64.55 \pm 4.25$ & $13.38 \pm 1.21$ & $0.82 \pm 0.00$ & $51.68 \pm 2.38$ & $0.19 \pm 0.00$ & $2.09 \pm 0.22$ & 0.9999 \\
\hline \multirow[t]{3}{*}{30} & 1 & $65.28 \pm 1.50$ & $13.53 \pm 0.97$ & $0.82 \pm 0.00$ & $50.51 \pm 0.31$ & $0.18 \pm 0.00$ & $2.17 \pm 0.07$ & 0.9999 \\
\hline & 5 & $62.66 \pm 3.02$ & $13.60 \pm 0.80$ & $0.81 \pm 0.00$ & $50.66 \pm 4.01$ & $0.20 \pm 0.01$ & $1.93 \pm 0.06$ & 0.9999 \\
\hline & 10 & $60.53 \pm 1.09$ & $13.37 \pm 2.12$ & $0.80 \pm 0.01$ & $51.70 \pm 2.75$ & $0.22 \pm 0.01$ & $1.79 \pm 0.26$ & 0.9999 \\
\hline \multirow[t]{3}{*}{40} & 1 & $64.46 \pm 3.18$ & $13.66 \pm 0.54$ & $0.82 \pm 0.02$ & $48.72 \pm 7.06$ & $0.18 \pm 0.03$ & $1.67 \pm 0.09$ & 0.9999 \\
\hline & 5 & $61.61 \pm 2.72$ & $13.55 \pm 0.34$ & $0.82 \pm 0.01$ & $47.32 \pm 2.05$ & $0.19 \pm 0.02$ & $1.56 \pm 0.05$ & 0.9999 \\
\hline & 10 & $60.09 \pm 4.97$ & $13.57 \pm 0.62$ & $0.86 \pm 0.02$ & $37.11 \pm 1.75$ & $0.12 \pm 0.03$ & $0.00 \pm 0.00$ & 0.9994 \\
\hline
\end{tabular}

membrane ${ }^{d}$

${ }^{a}$ The experimental results have been expressed as the average of 3 replicas $\pm s t \sqrt{n}(n=3, t=4.30(2 P=0.05)) .{ }^{b}$ Lifetime in the absence of oxygen.

${ }^{c}$ Lifetime in the presence of $20 \%$ of oxygen. ${ }^{d}$ Reference membrane prepared as in ref. 42.

effect was not observed in this case, probably due to the protection that the polymer provides to the oxygen-sensitive dye.

The oxygen sensing properties were evaluated by the reduction in the lifetime of emission (obtained with eqn (1)) when different oxygen concentrations are present. ESI-5† shows the phase shift measurement and decay plot obtained for the chip undergoing $40 \mathrm{~V} \mathrm{~cm}^{-1} / 1 \mathrm{~min}$. Similar behaviors were found for the rest of the sensing phases obtained by EPD. In all of them the phase shift was practically quenched by $30 \%$ oxygen, showing no differences in the lifetime between $30 \%$ and $100 \% \mathrm{O}_{2}$.

The response to oxygen is usually explained according to the Stern-Volmer equation. ${ }^{9}$ However, in this case the response between 0 and $30 \%$ does not follow the lineal behavior and the results have to be explained using a multi-site model, in which different types of oxygen quenching sites are present in the matrix. This behavior is typical in polymeric films due to the heterogeneity of the matrix where the dye is dispersed. ${ }^{32,43}$ The most simple is the two-site model (with each site having a linear behavior), proposed by Demas and co-workers. ${ }^{\mathbf{4 4}}$ (see eqn (2))

$$
\frac{\tau_{0}}{\tau}=\left[\frac{f_{1}}{1+k_{\mathrm{SV} 1} p \mathrm{O}_{2}}+\frac{f_{2}}{1+k_{\mathrm{SV} 2} p \mathrm{O}_{2}}\right]^{-1}
$$

where $\tau$ is the luminescence lifetime, the subscript " 0 " refers to the value in the absence of oxygen, $f_{1}$ and $f_{2}$ denotes the fraction of sites possessing a sensitivity to oxygen given by the SternVolmer constant $k_{\mathrm{SV} 1}$ and $k_{\mathrm{SV} 2}$ respectively, and $p \mathrm{O}_{2}$ is the partial pressure of oxygen.

Fig. 5a shows the calibration curve obtained using the Demas equation for the chip produced at $30 \mathrm{~V} \mathrm{~cm}^{-1}$ for 10 min. Similar behaviors were found for the rest of the chip obtained by EPD (see Fig. ESI- 6 and $7 \dagger$ ). For each sensing film the value of the Stern-Volmer constants was determined, and it was used to evaluate the oxygen sensitivity of the films. Table 2 shows the parameters obtained for the Demas model, which are practically the same for all the range of selected potentials and deposition times, except for the sensing film deposited at $40 \mathrm{~V} \mathrm{~cm}^{-1}$ for $10 \mathrm{~min}$. Its $k_{\mathrm{SV} 1}$ decreases compared to the rest ( $37 \mathrm{bar}^{-1} v s . \sim 50 \mathrm{bar}^{-1}$ ) probably due to the high conditions of potential and deposition time, both in

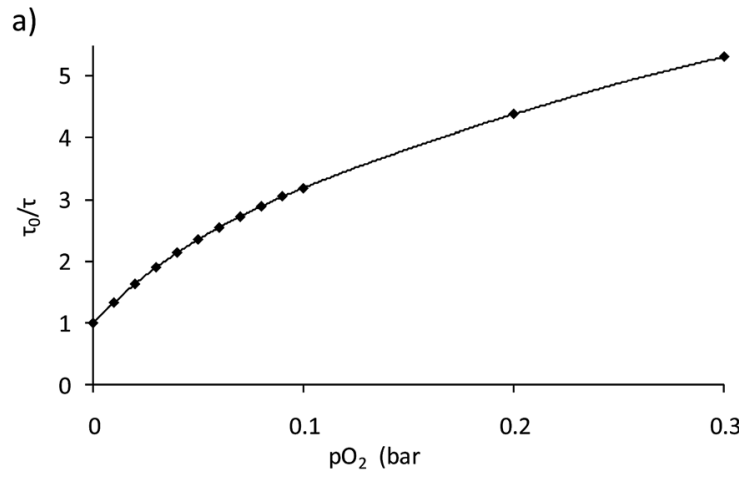

b)

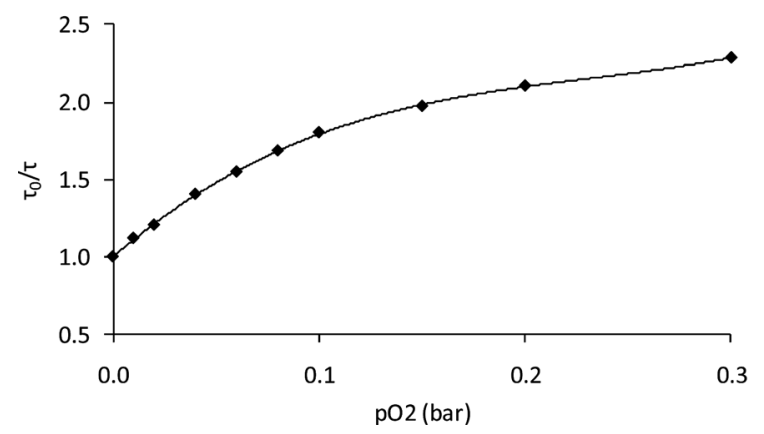

Fig. 5 Stern-Volmer plot for the sensing film obtained with $30 \mathrm{~V}$ $\mathrm{cm}^{-1} / 10$ min: (a) gas calibration; and (b) dissolved oxygen calibration. 
the upper border of the studied range. The correlation coefficients of the fittings $(r)$ shown in Table 2 confirm that eqn (2) is appropriate to adjust the data. According to the Demas model, the response to oxygen for all the chips suggests the existence of two sites within the matrix: a first fraction of sites $\left(f_{1}\right)$ possessing a high $k_{\mathrm{Sv} 1}$, and a second fraction of sites $\left(f_{2}\right)$, whose contribution is very small compared to $f_{1}$, presenting less sensitivity. The values for $k_{\mathrm{Sv} 1}$ found for the sensing films are in agreement with the results found for a classical PS membrane $\left(k_{\mathrm{SV} 1}=40.31 \pm 3.90 \mathrm{bar}^{-1}\right)^{25}$ and a PSMA membrane deposited over a glass support $\left(k_{\mathrm{Sv} 1}=49.25\right.$ $\pm 1.55 \mathrm{bar}^{-1}$; see Table 2), which were also the same than those obtained for a gold chip drop-coated with PSMA particles and dried under vacuum. The same oxygen behavior, regardless of the amount of particles deposited, hints that even at $250 \mathrm{~nm}$ thickness the sensitivity to oxygen is still restricted by the polymer permeability to oxygen as well as the distribution of the dye inside the polymeric material.

Since the physicochemical quenching reaction is a reversible process, the complete reversibility of the luminescence emission of the films allows us to continuously monitor the increasing and decreasing amounts of $\mathrm{O}_{2}$. Fig. 6 shows the operational stability for one of the replicas at $30 \mathrm{~V}$ $\mathrm{cm}^{-1} / 10 \mathrm{~min}$, which was conducted by measuring the phase shift under alternating nitrogen and oxygen saturated atmospheres.

The response $\left(t_{95}\right)$ of optical sensors can be defined as the time at which the signal reaches the $95 \%$ of the total response and it is an important feature in all chemical sensors, especially in medical monitoring where fast responses are desired. The $t_{95}$ was measured using a luminescence spectrophotometer by exposing the sensing films to alternating $\mathrm{N}_{2}$ and $\mathrm{O}_{2}$ atmospheres. All $t_{95}$ were shorter than $0.4 \mathrm{~s}$ when changing either from $0 \% \mathrm{O}_{2}$ to $100 \% \mathrm{O}_{2}$ or from $100 \% \mathrm{O}_{2}$ to $0 \% \mathrm{O}_{2}$. The response times are shorter than those reported in the literature for the same types of material. ${ }^{26,40}$ The nanoparticulated nature of the sensing layer and its thickness seem to be responsible for the improvement in $t_{95}$, which are in good agreement with other sensing layers of similar thickness. ${ }^{45,46}$

The limit of detection (LOD), calculated as the concentration of oxygen which produced an analytical signal three times the

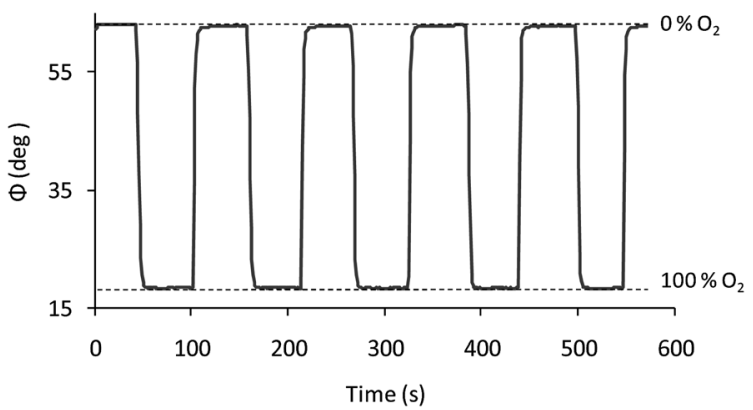

Fig. 6 Stability of chip $30 \mathrm{~V} \mathrm{~cm}-1 / 10 \mathrm{~min}$ when changing from nitrogen to oxygen consecutively.

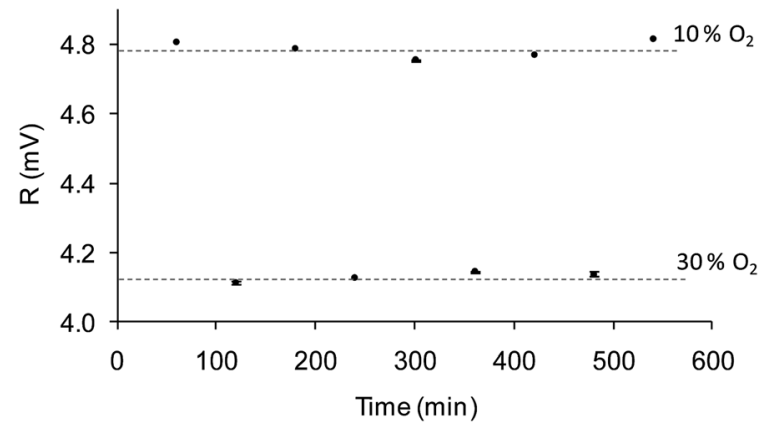

Fig. 7 Magnitude of the emission signal $(R$, in $\mathrm{mV}$ ) of the chip $30 \mathrm{~V}$

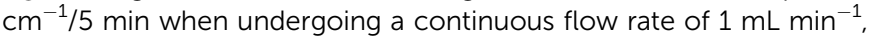
switching from $10 \%$ to $30 \%$ of oxygen every 60 minutes. Measurement at each concentration: 100 seconds taking 1 measurement per second.

standard deviation of ten injections of a blank ( $0 \%$ oxygen), was 0.02 mbar.

\subsection{Dissolved oxygen measurements}

The sensitivity to oxygen in the aqueous phase was also analyzed between 0 and $30 \%$ of oxygen bubbled into the water (a commercial Clark electrode was used to monitor the actual oxygen concentration in the water, which ranged from 0 and $11.28 \mathrm{ppm})$. Fig. 5b shows the Stern-Volmer plot which shows the following adjustment according to eqn (2): $f_{1}=0.66 ; k_{\mathrm{SV} 1}=$ $20.72 \mathrm{bar}^{-1}, f_{2}=0.34, k_{\mathrm{Sv} 2}=0.00 \mathrm{bar}^{-1}$; this decrease in sensitivity compared to the gas measurements is common in aqueous systems and it can be explained by the smaller number density of oxygen molecules in water and the relative hydrophilicity of the polymer. ${ }^{47}$ The lifetime of the nanoparticle dispersion in the absence of oxygen $(62 \mu \mathrm{s})$ did not agree well with the lifetime of the film produced by EPD in water $(\sim 50 \mu \mathrm{s})$, suggesting that the small layer produced by EPD is more affected by the aqueous environment than the bulk suspension. Nevertheless, the sensitivity of $20.72 \mathrm{bar}^{-1}$ and a LOD of 0.3 mbar confirm the suitability of the films to measure $\mathrm{O}_{2}$ in the physiological range.

Furthermore, in order to evaluate the attachment of the nanoparticles over the gold surface, the chips underwent a

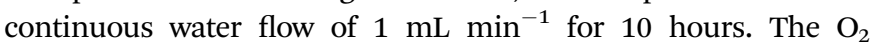
concentration in the water flow was changed from $10 \%$ to $30 \% \mathrm{O}_{2}$ consecutively, and the $R$ value of the modulated emission signal was recorded for 100 seconds every 60 minutes. If the sensing nanoparticles leach out of the chip, the intensity emission (i.e. $R$ value of the emission signal) will decrease for any of the oxygen concentration. Fig. 7 shows the average value of the measurements at each oxygen concentration for chip $30 \mathrm{~V} \mathrm{~cm}^{-1} / 5$ min with its error (calculated using Student's $t$-test with $n=100$ and $\alpha=0.025$ ). The same level of $R$ with a small error is reached for each concentration, confirming that the measurement is stable and there is no removal of the nanoparticles from the gold surface.

The same procedure was followed to analyze the stability of the chip towards buffer solutions at the physiological range and different ionic strengths. The results showed no lixiviation of the particles from the surface. It would be interesting to know 
how the ionic strength and $\mathrm{pH}$ could affect the sensitivity of the EPD sensing chips for specific applications and should be taken into account for future research.

\section{Conclusions}

Optical oxygen sensing films have been developed by electrophoretic deposition of polymeric nanoparticles based on the poly(styrene-co-maleic anhydride) polymer and the luminescent oxygen sensitive dye PtTFPP. The carboxylic groups present in the particles surface are responsible for their high stability in water and allowed anodic EPD to be performed at different potential and deposition times.

The amount and morphology of the particles deposited were evaluated according to the SEM photographs and by analyzing the magnitude $R$ of the emission collected for the different times and potentials. The results show that the amount of polymer deposited is increased when increasing both the deposition time and potential. SEM confirms a homogeneous distribution of the particles over the surface, with a single layer of particles.

Furthermore, full characterization of the chips covered with the oxygen sensing films was carried out both in gas and aqueous phases. All the chips showed similar behavior, regardless of applied potential or time, with $k_{\mathrm{Sv} 1}$ from 45 to $51.70 \mathrm{bar}^{-1}$. Due to the small thicknesses of the films (about hundreds of nanometers), short response times (less than $0.4 \mathrm{~s}$ ) were obtained. In addition, the ability of the sensing films to measure dissolved oxygen was also evaluated showing a $k_{\mathrm{SV} 1}$ of $20.72 \mathrm{bar}^{-1}$. The nanoparticles were well attached to the gold surface as they did not leach when undergoing a continuous water flow for 10 hours.

We can conclude that EPD of polymeric oxygen-sensitive nanoparticles is a suitable method for the development of optical sensing films. This technique can be applied to different kinds of conductive substrates. Advantageously, these films could be integrated in complex microdevice geometries such as microrobots and MEMS. The use of polymers with carboxylic groups allows further covalent crosslinking of biomolecules. In addition, multi-deposition of different optical indicators could be also feasible in order to develop multiparametric sensing phases for a variety of applications.

\section{Acknowledgements}

We acknowledge financial support for this work by the Regional Government of Andalusia (Excellence projects P07-FQM-2625 and P07-FQM-2738) and the Spanish Ministry of Economy and Competitiveness (CTQ2011-25316).

\section{References}

1 N. Galloway, W. Amoaku, P. Galloway and A. Browning, Common Diseases of the Conjunctiva and Cornea, in Common Eye Diseases and their Management, Springer, London, 2006, pp. 45-60.
2 C. A. K. Lange, P. Stavrakas, U. F. O. Luhmann, D. J. de Silva, R. R. Ali, Z. J. Gregor and J. W. B. Bainbridge, Am. J. Ophthalmol., 2011, 152, 406-412.

3 W. Abdallah, H. Ameri, E. Barron, G. J. Chader, E. Greenbaum, D. R. Hinton and M. S. Humayun, Invest. Ophthalmol. Visual Sci., 2011, 52, 1035-1042.

4 I. A. Barbazetto, J. Liang, S. Chang, L. Zheng, A. Spector and J. P. Dillon, Exp. Eye Res., 2004, 78, 917-924.

5 S. E. Lyshevski, MEMS and NEMS: Systems, Devices, and Structures, CRC PressINC, 2002.

6 W. H. Ko, Sens. Actuators, A, 2007, 136, 62-67.

7 S. Saliterman, Fundamentals of bioMEMS and medical microdevices, Wiley-Interscience, 2006.

8 O. S. Wolfbeis, J. Mater. Chem., 2005, 15, 2657-2669.

9 J. R. Lakowicz, Principles of fluorescence spectroscopy, Springer, 2006.

10 F. Baldini, Anal. Bioanal. Chem., 2009, 393, 1089-1090.

11 O. Ergeneman, G. Chatzipirpiridis, J. Pokki, M. MarínSuárez, G. A. Sotiriou, S. Medina-Rodríguez, J. F. Fernández-Sanchez, G. Fernández, A. S. Pane and B. J. Nelson, IEEE Trans. Biomed. Eng., 2012, 59, 31043109.

12 B. J. Nelson, I. K. Kaliakatsos and J. J. Abbott, Annu. Rev. Biomed. Eng., 2010, 12, 55-85.

13 O. Ergeneman, J. J. Abbott, G. Dogangil and B. J. Nelson, Functionalizing intraocular microrobots with surface coatings, 2008.

14 O. Ergeneman, G. Dogangil, M. P. Kummer, J. J. Abbott, M. K. Nazeeruddin and B. J. Nelson, IEEE Sens. J., 2008, 8, 29-37.

15 J. Pokki, O. Ergeneman, K. M. Sivaraman, B. Ozkale, M. A. Zeeshan, T. Luhmann, B. J. Nelson and S. Pane, Nanoscale, 2012, 4, 3083-3088.

16 A. L. Rogach, N. A. Kotov, D. S. Koktysh, J. W. Ostrander and G. A. Ragoisha, Chem. Mater., 2000, 12, 2721-2726.

17 L. Besra and M. Liu, Prog. Mater. Sci., 2007, 52, 1-61.

18 A. R. Boccaccini, S. Keim, R. Ma, Y. Li and I. Zhitomirsky, J. R. Soc., Interface, 2010, 7, S581-S613.

19 O. Yarimaga, B. Yoon, D.-Y. Ham, J. Lee, M. Hara, Y.-K. Choi and J.-M. Kim, J. Mater. Chem., 2011, 21, 18605-18612.

20 Z. Sun, L. Jin, S. Zhang, W. Shi, M. Pu, M. Wei, D. G. Evans and X. Duan, Anal. Chim. Acta, 2011, 702, 95-101.

21 W. Shi, S. He, M. Wei, D. G. Evans and X. Duan, Adv. Funct. Mater., 2010, 20, 3856-3863.

22 J. R. Lakowicz, Principles of Fluorescence Spectroscopy, Kluwer Academic, New York, 1999.

23 D. B. Papkovsky, Sens. Actuators, B, 1993, 11, 293-300.

24 S. M. Borisov, T. Mayr, G. Mistlberger, K. Waich, K. Koren, P. Chojnacki and I. Klimant, Talanta, 2009, 79, 13221330.

25 S. Medina-Rodríguez, A. de la Torre-Vega, J. F. FernándezSánchez and A. Fernández-Gutiérrez, Sens. Actuators, B, 2013, 176, 1110-1120.

26 Y. Amao, T. Miyashita and I. Okura, J. Fluorine Chem., 2001, 107, 101-106.

27 W. Trettnak, C. Kolle, F. Reininger, C. Dolezal and P. O’Leary, Sens. Actuators, B, 1996, 36, 506-512. 
28 G. Mistlberger, K. Koren, E. Scheucher, D. Aigner, S. M. Borisov, A. Zankel, P. Pölt and I. Klimant, Adv. Funct. Mater., 2010, 20, 1842-1851.

29 M. Marín-Suárez, A. L. Medina-Castillo, J. F. FernándezSánchez and A. Fernández-Gutiérrez, Isr. J. Chem., 2012, 52, 264-275.

30 G. Mistlberger, A. Medina-Castillo, S. Borisov, T. Mayr, A. Fernández-Gutiérrez, J. Fernández-Sánchez and I. Klimant, Microchim. Acta, 2011, 172, 299-308.

31 G. n. Mistlberger, S. M. Borisov and I. Klimant, Sens. Actuators, B, 2009, 139, 174-180.

32 S. Borisov and I. Klimant, Microchim. Acta, 2009, 164, 7-15.

33 B. Ferrari and R. Moreno, J. Eur. Ceram. Soc., 2009, 30, 10691078.

34 C. Freitas and R. H. Müller, Int. J. Pharm., 1998, 168, 221-229.

35 G. Garnier, M. Duskova-Smrckova, R. Vyhnalkova, T. G. M. van de Ven and J.-F. Revol, Langmuir, 2000, 16, 3757-3763.

36 J. D. Ferry, D. C. Udy, F. C. Wu, G. E. Heckler and D. B. Fordyce, J. Colloid Sci., 1951, 6, 429-442.

37 E. R. Garrett and R. L. Guile, J. Am. Chem. Soc., 1951, 73, 4533-4535.

38 S. Banerjee, K. Sen, T. K. Pal and S. K. Guha, Int. J. Pharm., 2012, 436, 786-797.
39 H. C. Hamaker, Trans. Faraday Soc., 1940, 35, 279-287.

40 S.-K. Lee and I. Okura, Anal. Commun., 1997, 34, 185188.

41 E. Dulkeith, A. C. Morteani, T. Niedereichholz, T. A. Klar, J. Feldmann, S. A. Levi, F. C. J. M. van Veggel, D. N. Reinhoudt, M. Müller and D. I. Gittins, Phys. Rev. Lett., 2002, 89, 203002.

42 M. Marín-Suárez, B. F. E. Curchod, I. Tavernelli, U. Rothlisberger, R. Scopelliti, I. Jung, D. Di Censo, M. Grätzel, J. F. Fernández-Sánchez, A. FernándezGutiérrez, M. K. Nazeeruddin and E. Baranoff, Chem. Mater., 2012, 24, 2330-2338.

43 M. Marin-Suarezdel Toro, J. F. Fernandez-Sanchez, E. Baranoff, M. K. Nazeeruddin, M. Graetzel and A. Fernandez-Gutierrez, Talanta, 2010, 82, 620-626.

44 J. N. Demas and B. A. DeGraff, Sens. Actuators, B, 1993, 11, 35-41.

45 S. M. Borisov, D. L. Herrod and I. Klimant, Sens. Actuators, B, 2009, 139, 52-58.

46 T. Mayr, S. M. Borisov, T. Abel, B. Enko, K. Waich, G. n. Mistlberger and I. Klimant, Anal. Chem., 2009, 81, 6541-6545.

47 C. McDonagh, B. D. MacCraith and A. K. McEvoy, Anal. Chem., 1998, 70, 45-50. 